\title{
VARIATION OF THE MEDIAN NERVE COURSE AND ITS CLINICAL IMPORTANCE
}

\author{
Zora Haviarova $^{\mathrm{a}, \mathrm{b} *}$, Hisham El Falougy ${ }^{\mathrm{a}, \mathrm{b}}$, Anna Killingerova ${ }^{\mathrm{a}}$, Viktor Matejcik ${ }^{\mathrm{c}}$ \\ ${ }^{a}$ Institute of Anatomy, Faculty of Medicine, Comenius University, Bratislava, Slovak Republic \\ ${ }^{b}$ Department of Anatomy, Slovak Medical University, Bratislava \\ c Department of Neurosurgery, Faculty of Medicine, Comenius University \\ e-mail: zora.haviarova@fmed.uniba.sk
}

Received: June 15, 2009; Accepted (with revision): October 30, 2009

Key words: Variation/Course/Median Nerve/Formation

\begin{abstract}
Aims and methods: In our work we present and describe the variation of the course of the median nerve found in both upper limbs of one of the cadavers in our Institute of Anatomy (Medical Faculty, Comenius University, Bratislava, Slovakia) during the students dissection of the peripheral nerves and vessels.

Results and conclusion: This non-standard course of the median nerve was compared with a standard course described in the anatomical literature and atlases, and confronted with the variations of the median nerve found and its course described in the available literature. We also provide some clinical implications of such peripheral nerve variability because understanding such anomalies is important in the diagnosis of unexplained clinical signs and symptoms as well as during nerve blocks and certain surgical procedures around the neck and proximal arm.
\end{abstract}

\section{INTRODUCTION}

The median nerve (C5-Th1) is formed by union of: medial root from the medial cord (C8-Th1) and lateral root from the lateral cord (C5-C7) of the brachial plexus (C5-Th1) anterior or lateral to the third part of axillary artery. In the arm the nerve passes at first lateral to brachial artery (near the insertion of musculus coracobrachialis), then crosses in front of (rarely behind) the artery, descending medial to it in the cubital fossa where it passes posterior to the bicipital aponeurosis and anterior to the brachialis muscle without giving out any branches. In the forearm, it passes between the heads of pronator teres muscle and crosses lateral to the ulnar artery. Median nerve descends after that between flexor digitorum superficialis and flexor digitorum profundus muscles. Near the retinaculum flexorum the nerve descends lateral to musculus flexor digitorum superficialis, and passes to the palm between the muscle and retinaculum flexorum. In forearm and palm it gives motor branches for the flexors and sensitive branches to the skin of lateral side of the palm. The previous mentioned story of the median nerve recorded to occur in $82.8 \%$ of 1000 dissections (Fig. 1 and Fig. 2) $\left(\right.$ ref. $\left.^{1-6}\right)$.

\section{MATERIAL AND METHODS (CASUISTRY)}

In the cadaverous material of our Institute of Anatomy an atypical course of the median nerve in both upper limbs of cadaver of a 60 year old man was found during a student dissection on the peripheral nerves and vessels. In the right upper limb, the median nerve was formed in the infraclavicular part of brachial plexus in axilla by uniting its both roots: medial and lateral roots coming respectively from the medial and lateral cords of the brachial plexus, behind the axillary artery. From the lateral cord arose the musculocutaneous nerve too. From the medial cord arose ulnar nerve, medial cutaneous nerve of the arm and medial cutaneous nerve of the forearm. From the posterior cord arose axillary nerve and radial nerve without any further variation in their story (Fig. 3 and 4). The axillary artery continues its story as brachial artery, which also courses in front of the median nerve. In the left upper limb, the median nerve was also formed from the infraclavicular part of the brachial plexus in axilla, with the typical union of medial and lateral roots from the medial and lateral cords of brachial plexus. The cords of the brachial plexus (medial, lateral and posterior) were in typical order around the axillary artery that means from medial, lateral and posterior sides. The axillary artery continues its story as the brachial artery, however in continuation axis we found only the deep brachial artery, the brachial artery itself passes through the fork of the median nerve and in front of it along the whole of its course (Fig. 5 and 6). We recorded no other variations in formation or course of other nerves of the infraclavicular part of the brachial plexus. In the next dissected story of the axillary and brachial arteries, we also found no variations.

\section{DISCUSSION}

The found variabilities in the course of the median nerve were interesting as every arm showed different variants in formation of the median nerve. The upper mentioned variations in forming and constitution of the median nerve from medial and lateral cords are conceded by both the world known anatomical literature: even Gray's Anatomy and Cunningham's anatomy do not describe the percentage of these variations ${ }^{1,7}$. Detailed and broader information on the variations in formation 


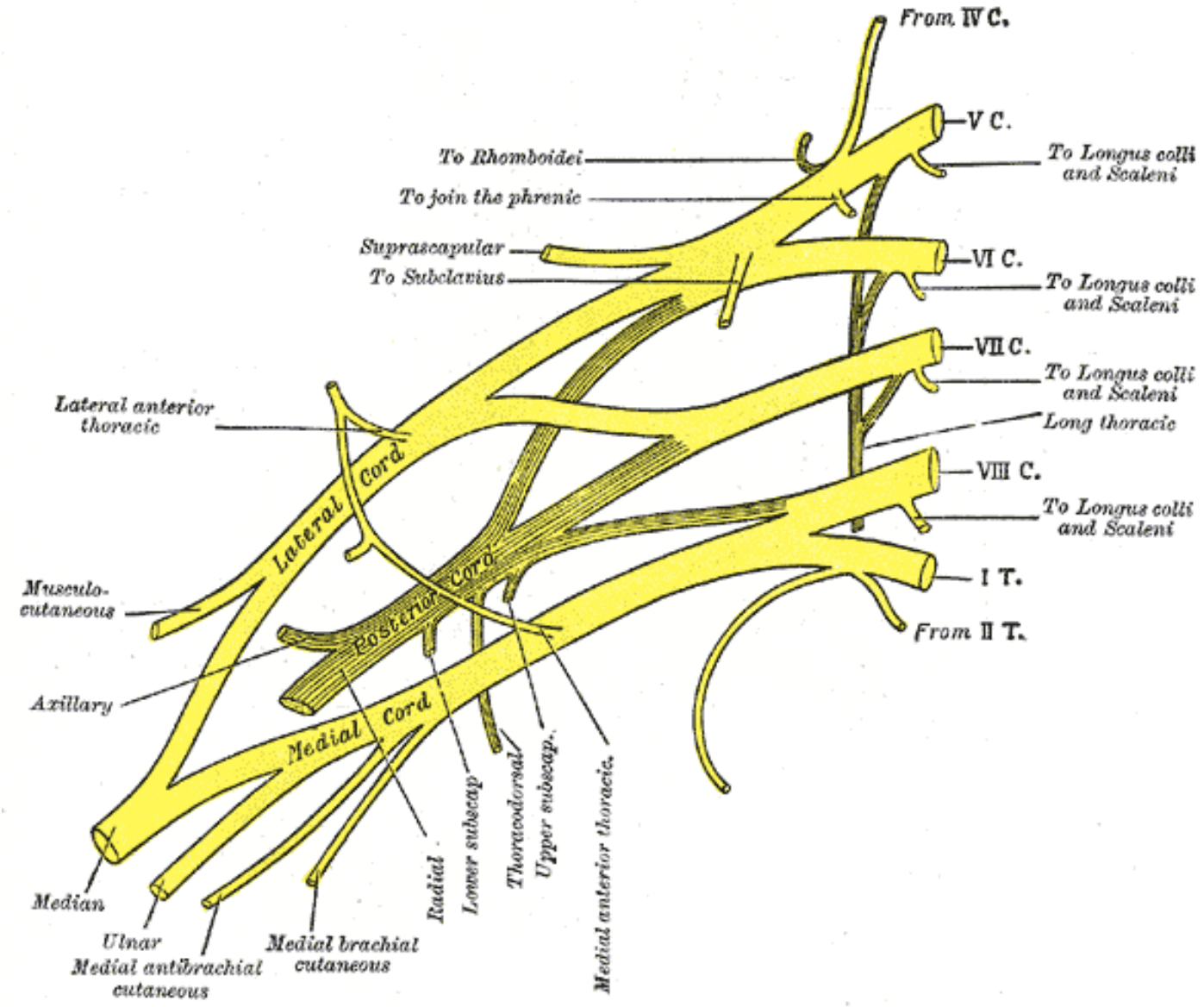

Fig. 1. An usual arrangment of the infraclavicular part of the brachial plexus ${ }^{3}$.

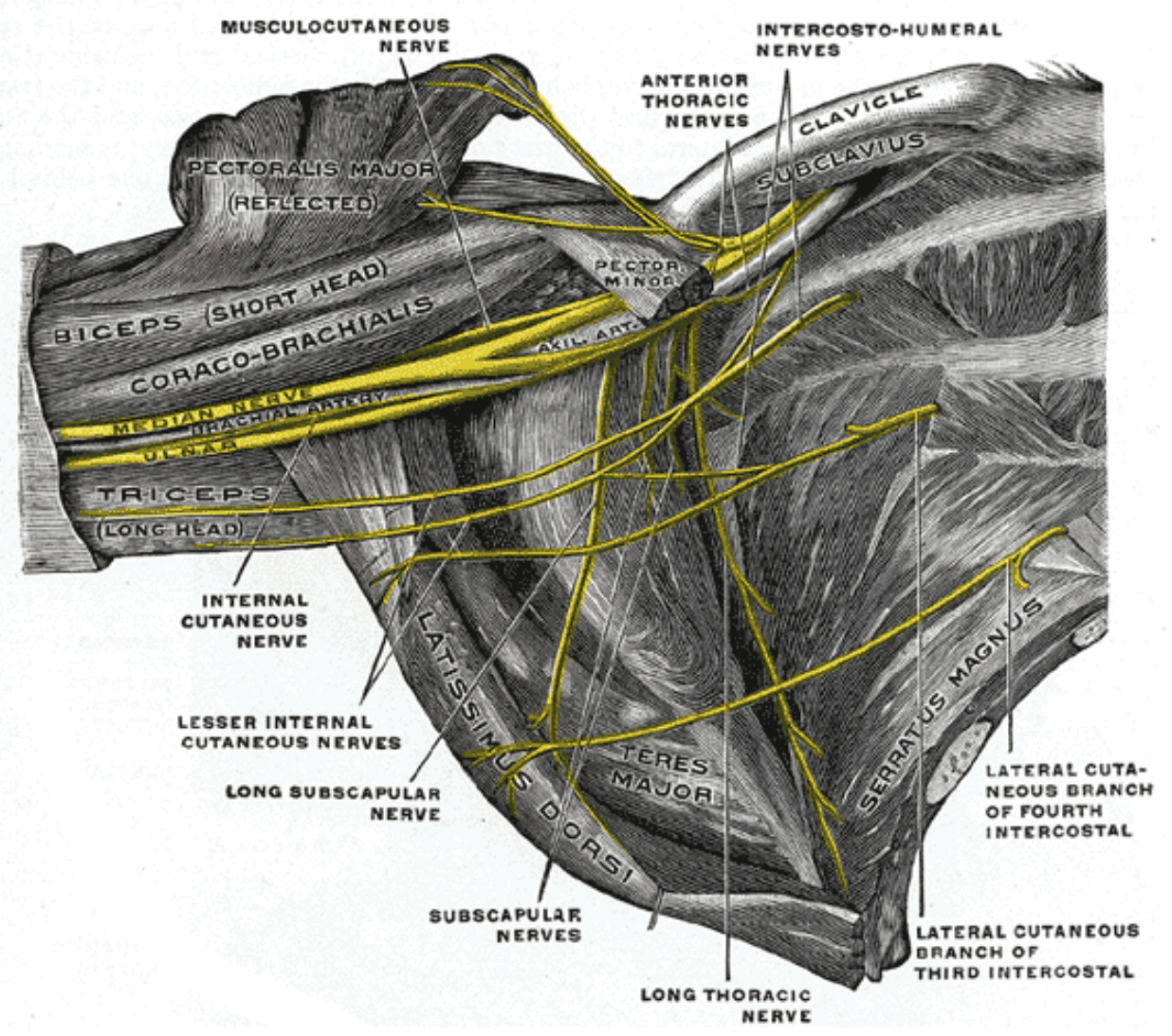

Fig. 2. Muscles and nerves of the axillar region ${ }^{3}$. 


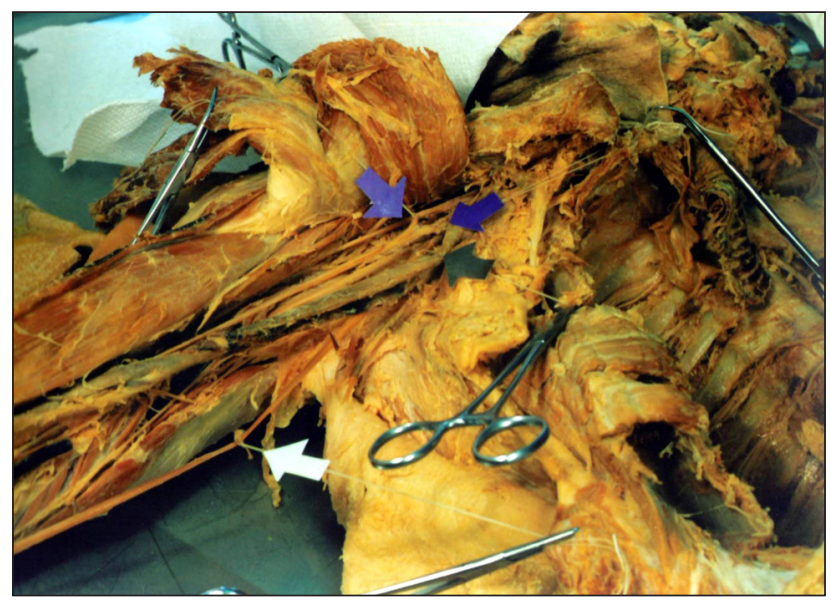

Fig. 3. Right upper limb dissected infraclavicular part of the brachial plexus. 1. radix lateralis n. mediani, 2. radix medialis n. mediani, 3 . a. brachialis, 4 . n. ulnaris.

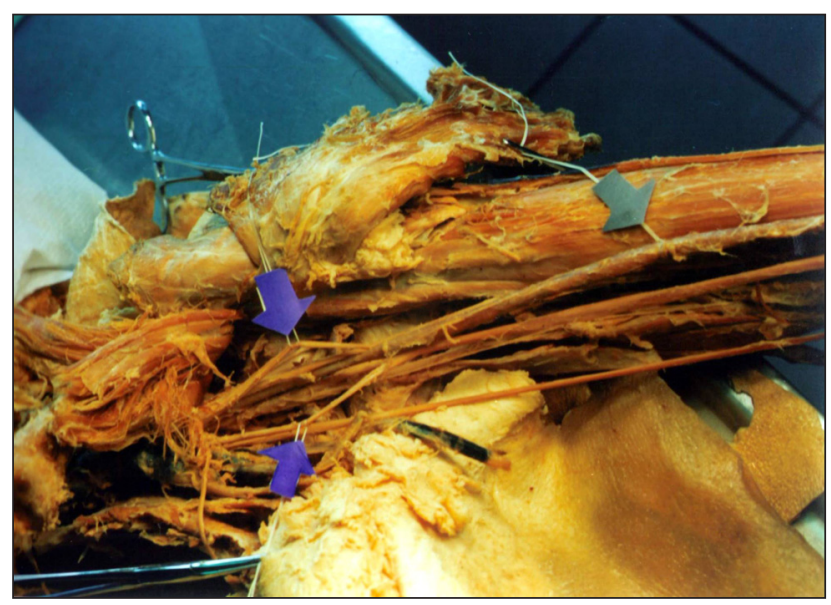

Fig. 5. Left upper limb dissected infraclavicular part of the brachial plexus. 1. radix medialis n. mediani, 2. radix lateralis n. mediani, 3. a. brachialis.

and story of the median nerve is given by Bergman, Afifi and Miyauchi in the Illustrated Encyclopaedia of Human Anatomic Variations, but even these authors did not mention percentage of forming of these variations we found ${ }^{8}$. Variation in the left arm is predicted to cause some clinical symptoms, but now and after many years post-mortem the examination could not be realised.

The anomalies in the formation of the nerves of the upper limbs have been described by several authors: Uzun, for example, reported the unusual unilateral median nerve formation of four roots in the left upper extremity of a 66 year old man cadaver, where three of them were from the lateral fascicle and two of them were communicating with the musculocutaneous nerve ${ }^{9}$. Badawoud showed 4 types of anomalies in the median nerve formation found on 48 upper extremities of the 24 cadavers. The found anomalies (usually on the left side) comprised of communicating branches between lateral and medial root of the median nerve, a communicating branch between lateral root of the median nerve and the medial cord of the

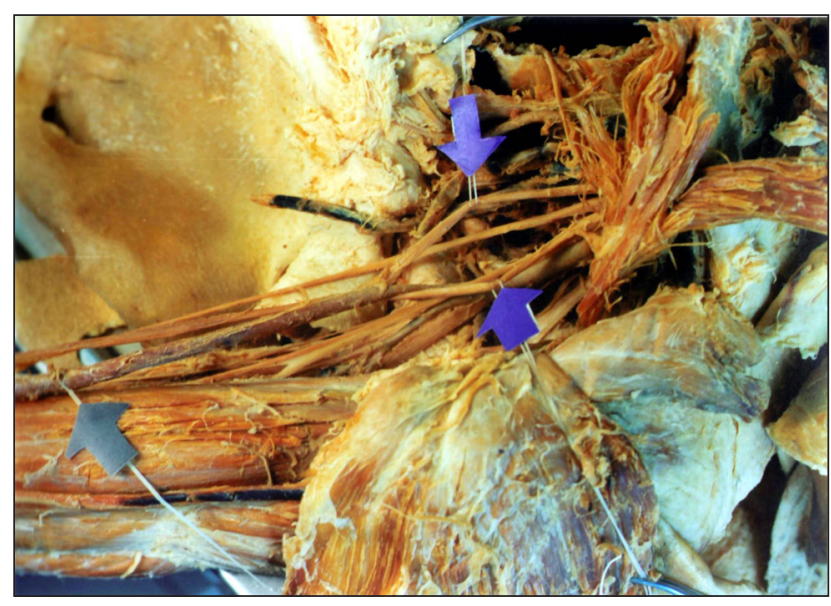

Fig. 4. Right upper limb dissected infraclavicular part of the brachial plexus (detailed view). 1. radix lateralis $n$. mediani, 2 . radix medialis $n$. mediani, 3. a. brachialis.

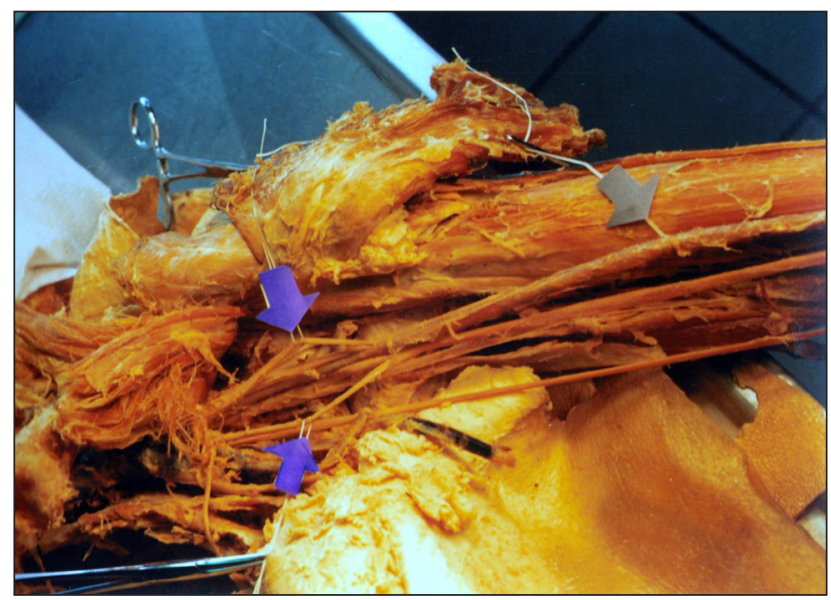

Fig. 6. Left upper limb dissected infraclavicular part of the brachial plexus (detailed view). 1. radix medialis n. mediani, 2. radix lateralis n. mediani, 3 . a. brachialis.

brachial plexus, communicating branches between lateral root of the median nerve and musculocutaneous nerve, unusually long roots of the median nerve ${ }^{10}$. Aggarwal described rare bilateral anomalous branching of the brachial plexus consisted of also anomalous left-sided formation of the median nerve: united of two medial and two lateral roots ${ }^{11}$. Suruchi showed an anomalous course of the right median nerve (found on 57 years old male cadaver) occurring medial to the axillary artery and having two communicating branches with musculocutaneous nerve ${ }^{12}$.

\section{CONCLUSION}

The next story and branching of the median nerve in both upper limbs did not show any variations, also no variations were found in the next course of the axillary and brachial arteries in both upper limbs. Variations of the course of peripheral nerves in the upper extremity are clinically and surgically important. Many anomalies of the 
nerve structures are sources of atypical clinical and electromyographic findings and source of diagnostic mistakes and embarrassment. Knowledge of the anatomical variations of peripheral nerves may contribute to explain the atypical clinical signs and are particularly important for surgeons engaged in reconstruction operations of nerve plexuses and their branches. It is useful to think not only for these variations, but their relationship to the major blood vessels, since the topographical relationships of nerves and arteries may be different, and may cause difficulties for emergency surgery. In the case of bilateral variations are not always act the same type of variation.

\section{REFERENCES}

1. Gray's Anatomy. 39th Edition. Churchill Livingston, 2005, p. 1600

2. Gray H. Anatomy of the Human Body. Philadelphia: Lea \& Febiger, 1918; Bartleby.com, 2000. www.bartleby.com/107/.

3. Kahle W, Leonhardt H, Platzer W. Color Atlas Text of Human Anatomy.Vol 3. George Thieme Verlag, Stuttgart. 1993. p. 376.
4. Holomáňová A, Brucknerová I. Srdcovocievna sústava (anatomické názvy). Elán, Bratislava, 2000. p. 70.

5. Holomáňová A, Brucknerová I. Anatomické názvy II. Elán, Bratislava, 2002. p. 144.

6. Holomáňová A. Brucknerová I. Anatomické názvy III. Elán, Bratislava, 2003. p. 156.

7. Cunningham's Textbook of Anatomy. 12th Edition. International student edition. Oxford Medical Publications, 1995, p. 1078.

8. Bergman RA, Afifi AK, Miyauchi R. Illustrated Encyclopedia of Human Anatomic Variations: Part III: Nervous System: Plexuses. Available on: http://lib.cpums.edu.cn/jiepou/tupu/atlas/www. vh.org/adult/provider/anatomy/AnatomicVariants/AnatomyHP. html

9. Uzun A, Seelig L L Jr. A variation in the formation of the median nerve: communica-ting branch between the musculocutaneous and median nerves in man. Folia Morphol 2001; 60(2):99-101.

10. Badawoud Mohammed HM. A Study on the Anatomical Variations of Median Nerve Formation. Bahrain Medical Bulletin 2003; 25(4).

11. Aggarwal A, Harjeet K, Sahni D, Aggarwal A. Bilateral multiple complex variations in the formation and branching pattern of brachial plexus. Surg Radiol Anat 2009 Apr 22. [Epub ahead of print].

12. Suruchi S, Vani VR, Roopa R. Variations in brachial plexus and the relationship of median nerve with the axillary artery: a case report. J Brachial Plex Peripher Nerve Inj. 2007; 2:21. 